\title{
IgG and IgA with Potential Microbial-Binding Activity Are Expressed by Normal Human Skin Epidermal Cells
}

\author{
Dongyang Jiang ${ }^{1,2,3}$, Jing Ge 1,2, Qinyuan Liao ${ }^{1,2}$, Junfan Ma ${ }^{1,2}$, Yang Liu ${ }^{1,2}$, Jing Huang 1,2, \\ Chong Wang ${ }^{1,2}$, Weiyan Xu ${ }^{1,2}$, Jie Zheng ${ }^{4}$, Wenwei Shao ${ }^{1,2}$, Gregory Lee ${ }^{5}$ and \\ Xiaoyan Qiu ${ }^{1,2,3, *}$
}

1 Department of Immunology, School of Basic Medical Sciences, Peking University, Beijing 100191, China; E-Mails: jiangdy@bjmu.edu.cn (D.J.); jing.ge.13@ucl.ac.uk (J.G.); 1qy19870604@bjmu.edu.cn (Q.L.); majunfan@gmail.com (J.M.); liu_yang95@126.com (Y.L.); huangjing82@bjmu.edu.cn (J.H.); cwang@bjmu.edu.cn (C.W.); xuweiyanpzy@gmail.com (W.X.); shaoww23@bjmu.edu.cn (W.S.)

2 Center for Human Disease Genomics, Peking University, Beijing 100191, China

3 Key Laboratory of Medical Immunology, Ministry of Health, Beijing 100191, China

4 Hematology Oncology Center, Beijing Children's Hospital, Beijing 100045, China; E-Mail: cutezjie@163.com

5 Andrology Laboratory, University of British Columbia Center for Reproductive Health, Vancouver, BC V6H 3N1, Canada; E-Mail: leecyg@gmail.com

* Author to whom correspondence should be addressed; E-Mail: qiuxy@bjmu.edu.cn; Tel.: +86-10-8280-5477; Fax: +86-10-8280-1149.

Academic Editor: Miroslav Blumenberg

Received: 16 October 2014 / Accepted: 7 January 2015 / Published: 23 January 2015

\begin{abstract}
The innate immune system of the skin is thought to depend largely on a multi-layered mechanical barrier supplemented by epidermis-derived antimicrobial peptides. To date, there are no reports of antimicrobial antibody secretion by the epidermis. In this study, we report the expression of functional immunoglobulin $\mathrm{G}(\mathrm{IgG})$ and immunoglobulin $\mathrm{A}$ (IgA), previously thought to be only produced by B cells, in normal human epidermal cells and the human keratinocyte line HaCaT. While B cells express a fully diverse Ig, epidermal cell-expressed IgG or IgA showed one or two conservative $\mathrm{VHDJ}_{\mathrm{H}}$ rearrangements in each individual. These unique VDJ rearrangements in epidermal cells were found neither in the B cell-derived Ig VDJ databases published by others nor in our positive controls. IgG and IgA from epidermal cells of the same individual had different VDJ rearrangement
\end{abstract}


patterns. IgG was found primarily in prickle cells, and IgA was mainly detected in basal cells. Both epidermal cell-derived IgG and IgA showed potential antibody activity by binding pathogens like Staphylococcus aureus, the most common pathogenic skin bacteria, but the microbial-binding profile was different. Our data indicates that normal human epidermal cells spontaneously express IgG and IgA, and we speculate that these Igs participate in skin innate immunity.

Keywords: immunoglobulin G; immunoglobulin A; human epidermis; VDJ rearrangement; microbial-binding

\section{Introduction}

Immunoglobulin (Ig), also known as antibody, is thought to be produced exclusively by B lineage cells but no other cell types. B cell-expressed Ig is one of the key molecules for humoral immune responses; it recognizes foreign pathogens, neutralizes them directly, or activates other immune cells to remove them [1]. However, over the past 10 years, there is growing evidence that many normal or malignant non-B lineage cells, including certain gland epithelial cells [2-7], germ cells [8], endothelial cells [9], cardiomyocytes [10], or neurons [11,12], can also express Ig, including IgM, $\operatorname{IgG}[13,14]$ and $\operatorname{IgA}[3,15-17]$. Both $\operatorname{IgG}$ and $\operatorname{IgA}$ derived from non-B cells promoted the survival and proliferation of cells [18-22]. Gland epithelial cell-derived IgM even exhibited natural antibody activity [6].

The skin is a barrier that limits the invasion and growth of pathogenic bacteria. Cutaneous antimicrobial defense mechanisms include the mechanical rigidity of the stratum corneum and its low moisture content, stratum corneum lipids, the production of lysozyme and antimicrobial peptides by the epidermis, acidity ( $\mathrm{pH} 5$ ), and defensins [23,24]. In addition, the skin supports the growth of commensal bacteria, such as Staphylococcus epidermidis, which protect the host from pathogenic bacteria, such as Staphylococcus aureus, both directly and indirectly [23,25]. There is, however, no direct evidence that Ig molecules can be expressed in the epidermis and contribute to antimicrobial activity. As long as 30 years ago, the cytoplasm of normal epidermal cells was reported to stain for IgG [26]. IgG and IgA deposits were frequently observed in epidermal cells and the epidermal stratum basale in several autoimmune diseases [27-29] and, occasionally, in normal skin [26,30]. In addition, several groups including us have reported that human malignant squamous cells, including esophageal, lung cancer and oral carcinoma, together with normal oral squamous cells adjacent to the tumors, frequently stained for $\operatorname{IgG}$ or $\operatorname{IgA}[5,19,31]$. Based on these findings, we proposed that Ig molecules could be expressed in the epidermis and might provide antimicrobial activity.

Our study shows that normal skin epidermal cells stain significantly for IgG and IgA. The abundance of both $\mathrm{IgG}$ and $\mathrm{IgA}$ in the epidermis is verified by Western blot analysis and, importantly, we find evidence that the rearranged $\operatorname{Ig} \gamma$ (IgG heavy chain) and $\operatorname{Ig} \alpha$ (IgA heavy chain) chains are transcribed in the epidermis. Unexpectedly, in each individual, the IgG and IgA heavy chain gene show unique VDJ rearrangements. Meanwhile, $\operatorname{IgG}$ and $\operatorname{IgA}$ protein and transcripts are also detected in $\mathrm{HaCaT}$, an immortal human keratinocyte cell line. IgG and IgA derive from epidermis tissue or keratinocyte 
HaCaT could each recognize several pathogens, especially Staphylococcus aureus. These data suggest that normal human epidermal cells can express IgG and IgA, with unique VDJ rearrangements, and that this Ig could contribute to the innate immune of the skin.

\section{Results and Discussion}

\subsection{Immunoglobulin $G(\operatorname{Ig} G)$ and Immunoglobulin A (IgA) Staining in Normal Human Epidermis}

In this study, we used two anti-human IgG antibodies, the commercial anti-human IgG antibody and RP215, a monoclonal antibody that specifically recognizes a unique glycosylated epitope on IgG heavy chains that is over-expressed in certain non-B cancer cells but not in B cells [32,33]. As in our previous observations using the commercial anti-human $\operatorname{IgG}$, both the epidermis and dermis stained, with the stronger staining in the dermis (Figure 1). Unexpectedly, RP215 stained the epidermis very strongly, but not the dermis. On the paraffin sections, we found strong positive staining by RP215 in cytoplasm of cells in the stratum spinosum and stratum granulosum, and weak positive staining in the stratum basale and stratum corneum (Figure 1A). On frozen sections by immunofluorescence, we found that RP215 strongly stained the stratum corneum and extracellular space, in addition to the cytoplasm of cells in the stratum spinosum and stratum granulosum (Figure 1B). The anti-human IgA showed obvious positive staining of the membranes and extracellular areas of epidermal cells, while their intracellular staining was weak. Exceptionally, basal cells stained strongly (Figure 1A). No immunoreactivity of anti-mouse or anti-rabbit IgG antibodies (as control) was observed in epidermal cells (Figure S1).
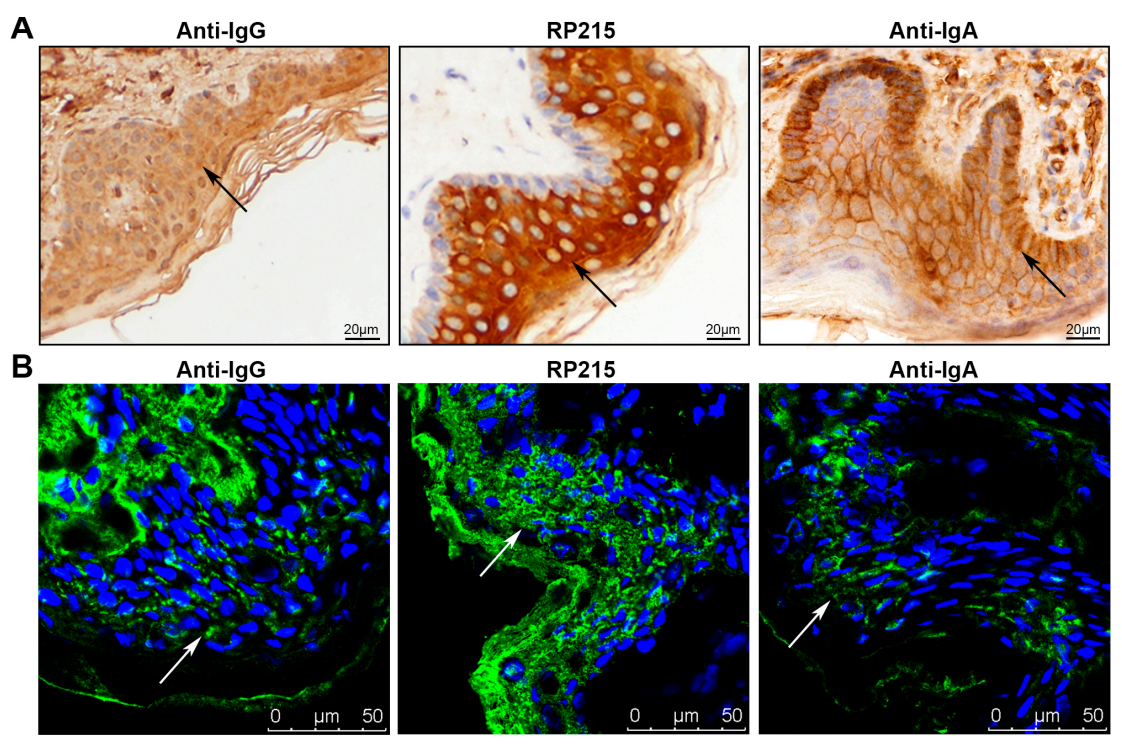

Figure 1. Immunoglobulin $\mathrm{G}(\operatorname{IgG})$ and immunoglobulin $\mathrm{A}(\operatorname{Ig} \mathrm{A})$ distribution in normal skin epidermis detected by immunostaining. (A) Immunohistochemical staining with commercial anti-IgG antibody, RP215 and anti-IgA antibody of paraffin-embedded sections of normal skin tissues. Arrows denote immunoreactivity of Ig; (B) Immunofluorescence staining with commercial anti-IgG antibody, RP215 and anti-IgA antibody in frozen sections of normal skin tissues. Green: immunostaining of Ig, blue: nucleus staining by Hochest 33342. Arrows denote immunoreactivity of Ig. 


\subsection{IgG and IgA in Epidermal Cells Confirmed by Western Blotting}

To confirm the presence of IgG and IgA, we separated the epidermal layer from the foreskin samples by Dispase II digestion [34,35] and extracted the protein. Western blotting for the IgG heavy chains used commercial anti-human IgG antibody and RP215, and the IgA heavy chains used anti-human IgA antibody.

Clearly, both anti-human IgG antibody and RP215 recognized the same band at about $M_{\mathrm{r}}$ 55,000 in all five samples, which corresponds to the molecular size for IgG heavy chain (Figure 2A). As expected, RP215 recognized IgG heavy chains in epidermis, but not serum, more effectively than the commercial anti-human IgG. For further identification, we purified the IgG from the epidermis using protein $\mathrm{G}$ sepharose, which can bind most IgGs. The purified IgG in the eluate was recognized by both the commercial anti-human IgG antibody and RP215 (Figure 2B). Mass spectra results show that the band at $M_{\mathrm{r}} 55,000$ bound by protein $\mathrm{G}$ contained segments of IgG heavy chain (Table S1).

The commercial anti-human IgA detected IgA heavy chain, at about $M_{\mathrm{r}} 65,000$, in all five samples (Figure 2A). Interestingly, the epidermis contained the protein band at about $M_{\mathrm{r}} 70,000$ that was also recognized by anti-IgA (Figure 2A). The change in molecular weight may result from a post-translational modification, such as glycosylation.

95\% cells of epidermis are keratinocytes. To further confirm the endogenous production of IgG and $\operatorname{IgA}$ in epidermal cells, we examined $\operatorname{IgG}$ and $\operatorname{IgA}$ expression in $\mathrm{HaCaT}$, a human immortalized keratinocyte cell line, by Western blotting. The immunoreactivity of IgG or IgA in HaCaT was similar with isolated epidermis, determined by commercial anti-human IgG antibody, RP215 and commercial anti-human IgA antibody (Figure 2A).

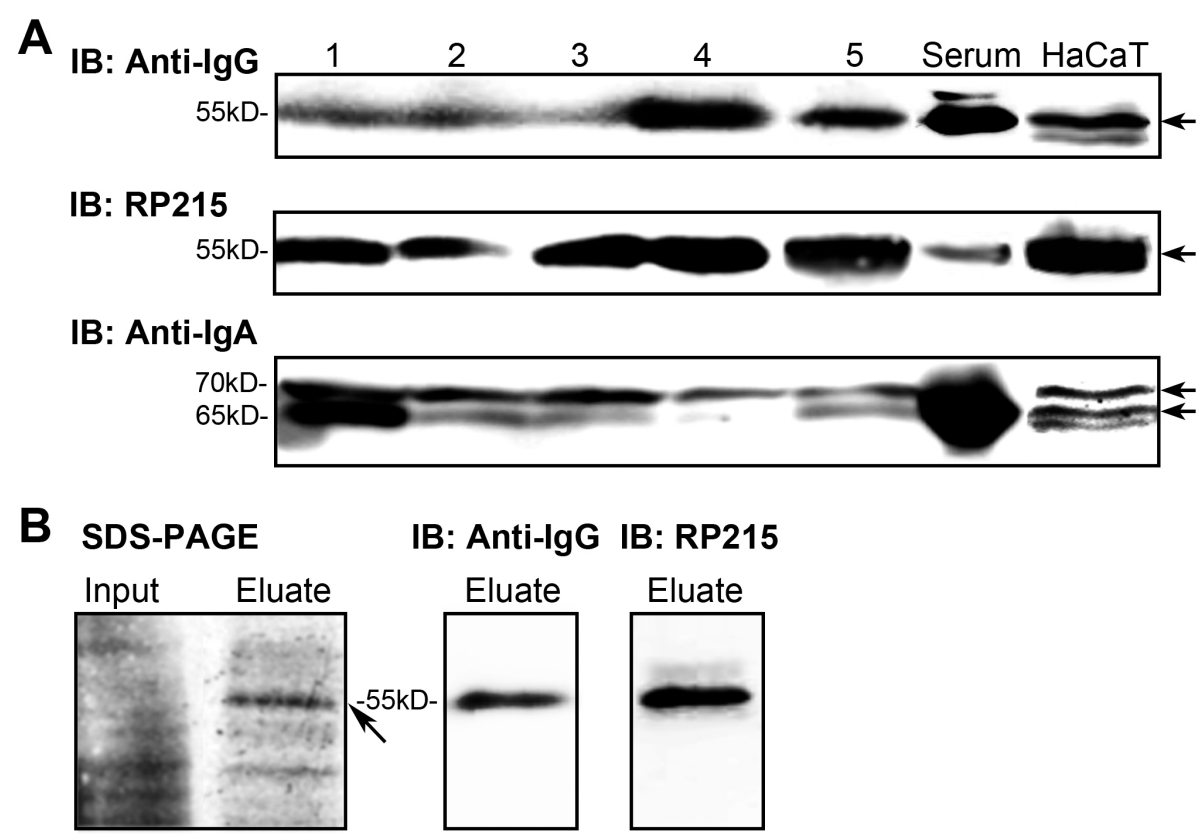

Figure 2. Expression of $\operatorname{IgG}$ and $\operatorname{IgA}$ in epidermal cells. (A) $\operatorname{IgG}$ or $\operatorname{IgA}$ expression in separated epidermal cells and HaCaT cell line determined by Western blotting using commercial anti-IgG antibody and RP215, or anti-IgA antibody, respectively. 1-5: epidermis samples. Arrows indicate immunoreactivity of $\operatorname{IgG}$ or $\operatorname{IgA}$; (B) IgG purification by affinity chromatography with protein $\mathrm{G}$ sepharose. The protein band indicated by the arrow was further analyzed by mass spectrometry. 


\subsection{Rearranged IgG and IgA Heavy Chains Are Transcribed in Epidermal Cells}

B lineage cells can produce abundant IgG and IgA. To test for possible contamination by B lymphocytes, we first examined the epidermal layer by immunohistochemistry for B lymphocytes, using anti-human CD20 antibody. The result clearly shows that no CD20-positive cells were found (Figure 3A). The isolated layers were proved only contained epidermis in which nearly all cells stained strongly for cytokeratin without dermis tissues through immunohistochemistry assay using anti-human pan-cytokeratin antibody (Figure 3A). Furthermore, RNA was extracted from the isolated epidermal layer and was reverse transcribed to cDNA. Contamination by $\mathrm{B}$ cells in the cDNA libraries was excluded by RT-PCR using the primers for amplifying CD19 gene, another specific marker for B cells. The cDNAs were tested for rearranged transcripts of $\operatorname{IgG}(\gamma)$ and $\operatorname{IgA}(\alpha)$ heavy chains by RT-PCR using primers for the variable regions of the Ig heavy chain gene, and the respective constant region of Ig $\gamma$ or Ig $\alpha$ chains. To detect Ig heavy chain gene rearrangements in the epidermis, we employed primers known to detect almost all $\mathrm{V}_{\mathrm{HDJ}} \mathrm{J}_{\mathrm{H}}$ rearrangements in B cells [36]. Rearranged Ig $\gamma$ and Ig $\alpha$ genes were successfully amplified from cDNA libraries of epidermis from two donors (Figure 3B). Furthermore, sequence analysis showed that all the epidermis-derived Ig $\gamma$ and Ig $\alpha$ genes had classical VDJ rearrangements, with typical $\mathrm{N}$ nucleotide and $\mathrm{P}$ nucleotide additions at the $\mathrm{V}-\mathrm{D}$ junctions and D-J junctions (Table S2) and that all rearrangements were functional, i.e., that no stop codons were introduced by mutations or junctions between $\mathrm{V}, \mathrm{D}$ and $\mathrm{J}$ segments. In addition, the constant region transcripts of Ig $\gamma$ and Ig $\alpha$ were detected in HaCaT keratinocytes.

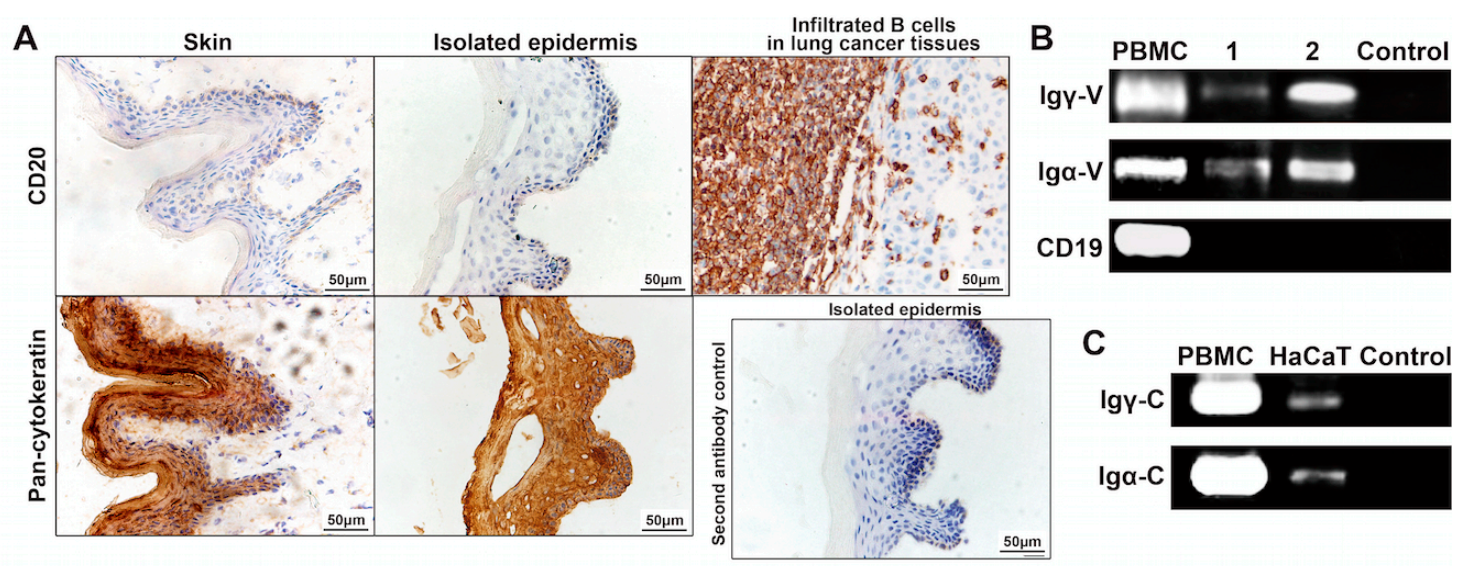

Figure 3. Transcription of $\operatorname{IgG}$ and $\operatorname{IgA}$ heavy chain gene in epidermal cells. (A) Immunohistochemistry staining of pan-cytokeratin (pan-CK) and CD20 in normal skin tissue and separated epidermis layer. Infiltrated $\mathrm{B}$ cells in the lung cancer tissue were used as positive control of CD20; (B) Rearranged IgG and IgA heavy chain variable region (Ig $\gamma-\mathrm{V}$ and $\operatorname{Ig} \alpha-\mathrm{V})$ gene transcripts in isolated epidermis detected by RT-PCR. CD19 transcripts were detected to evaluate possible B cell contamination in isolated epidermis. PBMC: peripheral blood mononuclear cell as positive control; 1 and 2: epidermis samples from Case 1 and Case 2; control: PCR reaction mixture without templates as negative control; (C) IgG and IgA heavy chain constant region (Ig $\gamma-\mathrm{C}$ and $\operatorname{Ig} \alpha-\mathrm{C}$ ) gene transcripts in $\mathrm{HaCaT}$ cell line detected by RT-PCR. PBMC as positive control and PCR reaction mixture without templates as negative control (control). 
Surprisingly, however, the epidermal cell-derived $\mathrm{V}_{\mathrm{H}} \mathrm{J}_{\mathrm{H}}$ rearrangements showed only one or two VDJ patterns in each individual compared with the diverse $B$ cell-derived $\mathrm{V}_{\mathrm{H}} \mathrm{JJ}_{\mathrm{H}}$ rearrangements observed in this study and elsewhere. The epidermis-derived Ig $\gamma$ gene showed only one VDJ pattern, VH1-2/DH5-18/JH6 in Case 1, and only one VDJ pattern, VH2-5/DH2-21/JH4 in Case 2. Epidermis-derived Ig $\alpha$ genes showed two VDJ patterns, VH7-4-1/D6-13/JH6 and VH5-10-1/D2-2/JH3 in Case 1, and two VDJ patterns, VH1-3/D4-17/JH1 and VH1-3/D4-17/JH4 in Case 2, respectively (Table 1). None of the epidermis-derived VDJ rearrangement patterns of either Ig $\gamma$ or Ig $\alpha$ chains was found in B cells in our study or in the NCBI database. Moreover, the epithelial Igy VDJ rearrangements differed from any IgG heavy chain genes discovered in epithelial cancer cells [37]. The epidermis-derived Ig $\gamma$ and Ig $\alpha$ sequences have been submitted to the GenBank database (GenBank Accession Numbers: JX420702-JX420707).

Generally, the B cell-derived $\mathrm{V}_{\mathrm{HDJ}} \mathrm{J}_{\mathrm{H}}$ rearrangements of Ig $\gamma$ chains resembles that of Ig $\alpha$ chains because both are derived from Ig $\mu$-expressing B cells, and class switch recombination changes only the constant region, from Ig $\mu$ to Ig $\gamma$ or Ig $\alpha$. Interestingly, there was no identity between the $\mathrm{V}_{\mathrm{H \gamma}} \mathrm{D}_{\gamma} \mathrm{J}_{\mathrm{H} \gamma}$ and $\mathrm{V}_{\mathrm{H \alpha}} \mathrm{D}_{\alpha} \mathrm{J}_{\mathrm{H} \alpha}$ rearrangements in the two cases studied (Table 1). This could suggest that epidermis-derived IgG and IgA might not arise by classical class switching.

Table 1. $\mathrm{VHDJ}_{\mathrm{H}}$ recombinations of $\mathrm{IgG}$ and $\mathrm{IgA}$ heavy chain gene in epidermal cells.

\begin{tabular}{|c|c|c|c|c|c|c|c|c|}
\hline \multirow[b]{2}{*}{ Case } & \multicolumn{4}{|c|}{$\operatorname{Ig} \gamma$} & \multicolumn{4}{|c|}{$\operatorname{Ig} \alpha$} \\
\hline & Clone & $\begin{array}{l}\text { No. of } \\
\text { Clones }\end{array}$ & $\begin{array}{c}\mathrm{V}_{\mathrm{H}} \mathrm{DJ}_{\mathrm{H}} \\
\text { Recombination }\end{array}$ & $\begin{array}{l}\text { V Segment } \\
\text { Identity } \\
\text { (\%) with } \\
\text { Germlines }\end{array}$ & Clone & $\begin{array}{l}\text { No. of } \\
\text { Clones }\end{array}$ & $\begin{array}{c}\mathrm{V}_{\mathrm{H}} \mathrm{DJ}_{\mathrm{H}} \\
\text { Recombination }\end{array}$ & $\begin{array}{l}\text { V Segment } \\
\text { Identity } \\
(\%) \text { with } \\
\text { Germlines }\end{array}$ \\
\hline \multirow{4}{*}{ Case 1} & 1 & 1 & $\begin{array}{c}\text { VH1-2*02/ } \\
\text { D5-18*01/JH6*03 }\end{array}$ & 98.0 & 1 & 1 & $\begin{array}{c}\text { VH7-4-1*02/ } \\
\text { D6-13*01/JH6*02 }\end{array}$ & 84.0 \\
\hline & 2 & 1 & $\begin{array}{c}\text { VH1-2*02/ } \\
\text { D5-18*01/JH6*03 }\end{array}$ & 98.8 & 2 & 1 & $\begin{array}{c}\text { VH7-4-1*02/ } \\
\text { D6-13*01/JH6*02 }\end{array}$ & 84.3 \\
\hline & 3 & 1 & $\begin{array}{c}\text { VH1-2*02/ } \\
\text { D5-18*01/JH6*03 }\end{array}$ & 98.4 & 3 & 1 & $\begin{array}{c}\text { VH5-10-1*01/ } \\
\text { D2-2*01/JH3*03 }\end{array}$ & 79.9 \\
\hline & 4 & 1 & $\begin{array}{c}\text { VH1-2*02/ } \\
\text { D5-18*01/JH6*03 }\end{array}$ & 98.4 & 4 & 1 & $\begin{array}{c}\text { VH5-10-1*01/ } \\
\text { D2-2*01/JH3*03 }\end{array}$ & 81.3 \\
\hline \multirow{5}{*}{ Case 2} & $1-6$ & 6 & $\begin{array}{c}\mathrm{VH} 2-5 * 02 / \\
\mathrm{D} 2-21 * 02 / \mathrm{JH} 4 * 02\end{array}$ & 96.3 & $1-2$ & 2 & $\begin{array}{c}\text { VH1-3*01/ } \\
\text { D4-17*01/JH1*01 }\end{array}$ & 77.4 \\
\hline & 7 & 1 & $\begin{array}{c}\mathrm{VH} 2-5 * 02 / \\
\mathrm{D} 2-21 * 02 / \mathrm{JH} 4 * 02\end{array}$ & 96.3 & 3 & 1 & $\begin{array}{c}\text { VH1-3*01/ } \\
\text { D4-17*01/JH1*01 }\end{array}$ & 78.8 \\
\hline & 8 & 1 & $\begin{array}{c}\text { VH2-5*02/ } \\
\text { D2-21*02/JH4*02 }\end{array}$ & 95.9 & 4 & 1 & $\begin{array}{c}\text { VH1-3*01/ } \\
\text { D4-17*01/JH1*01 }\end{array}$ & 79.2 \\
\hline & \multirow{2}{*}{9} & \multirow{2}{*}{1} & \multirow{2}{*}{$\begin{array}{c}\text { VH2-5*02/ } \\
\text { D2-21*02/JH4*02 }\end{array}$} & \multirow{2}{*}{95.9} & 5 & 1 & $\begin{array}{c}\text { VH1-3*01/ } \\
\text { D4-17*01/JH4*02 }\end{array}$ & 79.2 \\
\hline & & & & & 6 & 1 & $\begin{array}{c}\mathrm{VH} 1-3 * 01 / \\
\mathrm{D} 4-17 * 01 / \mathrm{JH} 4 * 02\end{array}$ & 78.8 \\
\hline
\end{tabular}


Table 1. Cont.

\begin{tabular}{|c|c|c|c|c|c|c|c|c|}
\hline \multirow[b]{2}{*}{ Case } & \multicolumn{4}{|c|}{$\operatorname{Ig} \gamma$} & \multicolumn{4}{|c|}{$\operatorname{Ig} \alpha$} \\
\hline & Clone & $\begin{array}{l}\text { No. of } \\
\text { Clones }\end{array}$ & $\begin{array}{c}\mathrm{V}_{\mathrm{H}} \mathrm{DJ}_{\mathrm{H}} \\
\text { Recombination }\end{array}$ & $\begin{array}{l}\text { V Segment } \\
\text { Identity } \\
\text { (\%) with } \\
\text { Germlines } \\
\end{array}$ & Clone & $\begin{array}{l}\text { No. of } \\
\text { Clones }\end{array}$ & $\begin{array}{c}\mathrm{V}_{\mathrm{H}} \mathrm{DJ} \mathrm{J}_{\mathrm{H}} \\
\text { Recombination }\end{array}$ & $\begin{array}{l}\text { V Segment } \\
\text { Identity } \\
\text { (\%) with } \\
\text { Germlines }\end{array}$ \\
\hline \multirow{8}{*}{$\begin{array}{c}\text { PBMC } \\
\text { (Control) }\end{array}$} & 1 & 1 & $\begin{array}{c}\text { VH1-69*13/ } \\
\text { D2-21*01/JH4*02 }\end{array}$ & 80.6 & 1 & 1 & $\begin{array}{c}\text { VH1-46*01/ } \\
\text { D2-21*02/JH4*02 }\end{array}$ & 78.1 \\
\hline & 2 & 1 & $\begin{array}{c}\text { VH1-8*01/ } \\
\text { D6-13*01/JH4*02 }\end{array}$ & 83.0 & 2 & 1 & $\begin{array}{c}\mathrm{VH} 1-2 * 02 / \\
\mathrm{D} 2-21 * 02 / \mathrm{JH} 4 * 02\end{array}$ & 81.9 \\
\hline & 3 & 1 & $\begin{array}{c}\text { VH1-46*01/ } \\
\text { D1-7*01/JH4*02 }\end{array}$ & 90.5 & 3 & 1 & $\begin{array}{c}\text { VH1-3*01/ } \\
\text { D1- } 7 * 01 / \mathrm{JH} 4 * 02\end{array}$ & 81.6 \\
\hline & 4 & 1 & $\begin{array}{c}\text { VH4-59*03/ } \\
\text { D6-6*01/JH6*02 }\end{array}$ & 94.8 & 4 & 1 & $\begin{array}{c}\text { VH4 } 4-59 * 08 / \\
\text { D2-8*02/JH4*02 }\end{array}$ & 82.5 \\
\hline & 5 & 1 & $\begin{array}{c}\text { VH3-11*04/ } \\
\text { D5-12*01/JH5*02 }\end{array}$ & 85.7 & 5 & 1 & $\begin{array}{c}\text { VH1-18*01/ } \\
\text { D3-3*01/JH4*02 }\end{array}$ & 81.9 \\
\hline & 6 & 1 & $\begin{array}{c}\text { VH4-34*01/ } \\
\text { D3-10*01/JH6*02 }\end{array}$ & 92.9 & & & & \\
\hline & 7 & 1 & $\begin{array}{c}\text { VH3-23*01/ } \\
\text { D6-13*01/JH4*02 }\end{array}$ & 91.7 & & & & \\
\hline & 8 & 1 & $\begin{array}{c}\text { VH3-74*03/ } \\
\text { D1-26*01/JH5*02 }\end{array}$ & 91.8 & & & & \\
\hline
\end{tabular}

\subsection{Epidermis-Derived IgG and IgA Recognized Foreign Pathogens}

As the first barrier of human body, the epidermis encounters and prevents various pathogens from entering, including bacteria and fungi. We tested the binding of IgG and IgA extracted from epidermis of five donors to E. coli strains DH10B and BL21, S. aureus strains Cowan I and ATCC 25923, a clinical isolate of $S$. epidermidis, and Candida albicans (C. albicans) strain SC5314, by ELISA. Of the five samples we examined, epidermis-derived Ig from most samples showed similar microbial-binding patterns. However, the reaction to different pathogens differed between IgG and IgA derived from epidermis. Epidermis-derived IgG could bind $S$. aureus strongly, as well as E. coli, and that epidermis-derived IgA mainly bound $S$. epidermidis and $S$. aureus, as well as $C$. albicans (Figure 4A). Furthermore, we detected the secretion of $\mathrm{IgG}$ and $\mathrm{IgA}$ in human keratinocyte cell line HaCaT by ELISA. Our results showed that microbial-binding IgG and IgA could be secreted to the culture supernatant, and that stimulation with microbes induced the secretion of either IgG or IgA with microbial-binding activity (Figure 4B). IgG spontaneously secreted by HaCaT could response to $S$. aureus ATCC 25923, and IgG binding to microbes, including $S$. aureus strains ATCC 25923 and Cowan I and E. coli DH10B, increased obviously after stimulation. Meanwhile, HaCaT-secreted IgA showed spontaneous anti-E. coli BL21 and $S$. aureus Cowan I activity, and after stimulation IgA binding ability to $S$. aureus, S. epidermidis and C. albicans increased obviously (Figure 4B). Furthermore, either HaCaT-secreted IgG or IgA stimulated by different microbe showed cross-recognition feature among different microbes. The microbial-binding profiles of HaCaT-secreted Ig were mostly consistent with epidermis tissue-derived Ig. These results suggest that epidermal cells could produce and secret Ig 
to recognize pathogens, and that epidermis-derived Ig is elevated after microbe stimulation and might participate in immune responses.

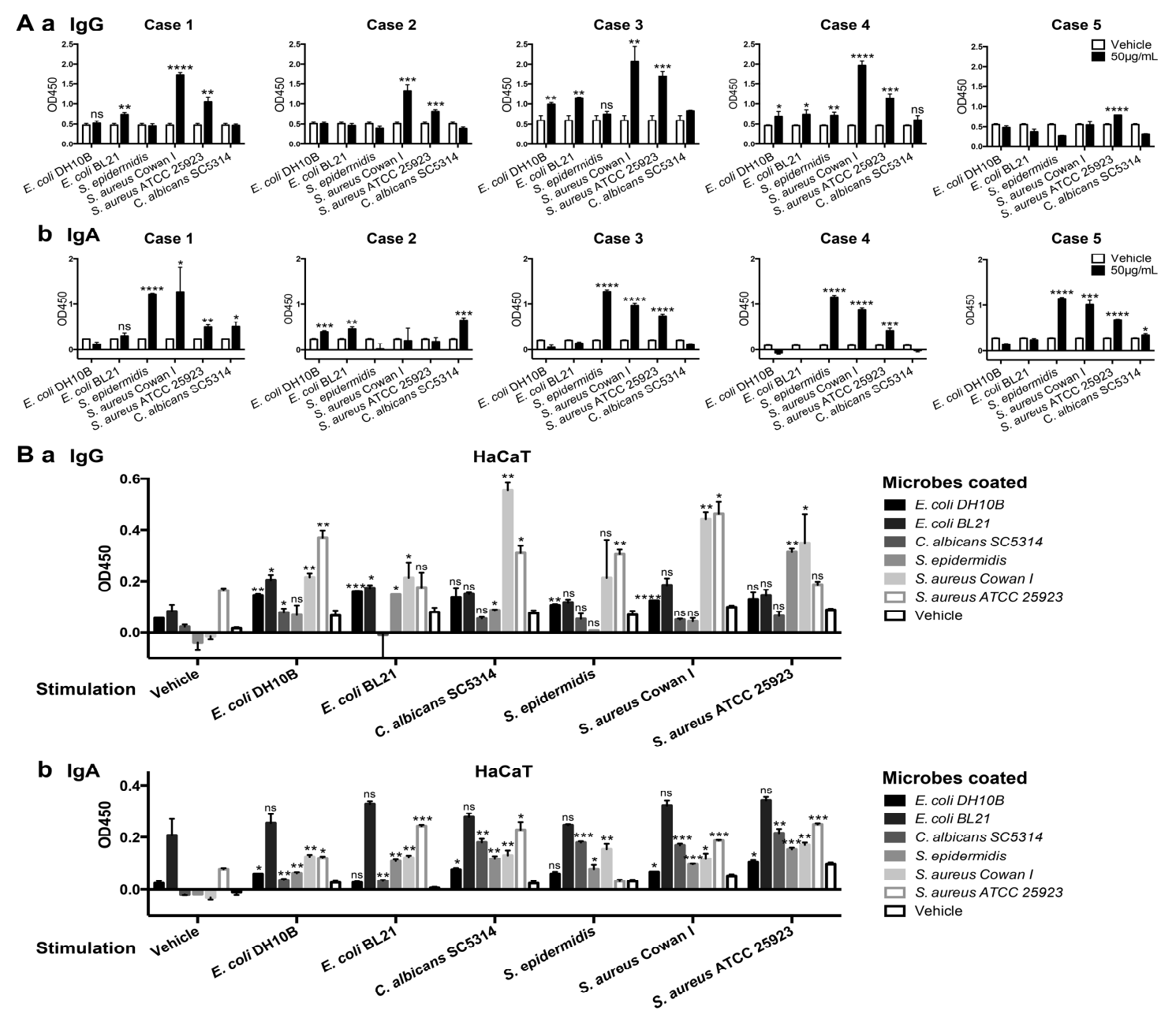

Figure 4. The binding of epidermis-derived $\operatorname{IgG}(\mathbf{A})$ and $\operatorname{IgA}(\mathbf{B})$ to E. coli strains DH10B and BL21, S. aureus strains Cowan I and ATCC 25923, clinical isolated strain of S. epidermidis, and C. albicans strain SC5314 was analyzed by ELISA. (A) Binding of $\operatorname{IgG}$ (a) and $\operatorname{IgA}$ (b) in epidermis tissue lysates from five healthy donors to microbes was analyzed by ELISA. $50 \mu \mathrm{g} / \mathrm{mL}$ microbes were coated for testing Ig binding, vehicle as negative control. Data are presented as mean $\pm \mathrm{SD}$. Student's $t$-tests were performed when mean of microbes-coated group was higher than vehicle control. Statistical significance: ns means no significant difference, $* p<0.05, * * p<0.01, * * * p<0.001, * * * * p<0.001$ vs. vehicle control; (B) The microbial-binding activity of secreted $\operatorname{IgG}$ (a) and $\operatorname{IgA}(\mathbf{b})$ by $\mathrm{HaCaT}$ was analyzed by ELISA. Cell culture supernatant was collected $24 \mathrm{~h}$ after stimulation with different microbes $(50 \mu \mathrm{g} / \mathrm{mL})$. IgG and $\operatorname{IgA}$ with microbial-binding activity were captured from the supernatant by different microbes coated at $50 \mu \mathrm{g} / \mathrm{mL}$ and were detected with anti-IgG and anti-IgA antibodies, respectively. All data are calibrated by minus OD450 of culture medium control and presented as mean \pm SD. Student's $t$-tests were performed when mean of microbe stimulation group was higher than vehicle stimulation control. Statistical significance: ns means no significant difference, ${ }^{*} p<0.05$, ${ }^{* *} p<0.01$, $* * * p<0.001, * * * * p<0.001$ vs. vehicle stimulation control. 


\subsection{Discussion}

Our study confirms our hypothesis that Ig molecules can be expressed in the epidermis, and they are involved in the innate immune of the skin.

Many reports previously showed that functional $\mathrm{IgG}$ and $\mathrm{IgA}$, each with unique VDJ rearrangement patterns, were significantly expressed in squamous cell carcinoma cells [5,19,31]. Furthermore, IgG staining in normal epidermis has been reported [31], but it remains unclear whether normal squamous cells, such as the epidermis, can rearrange Ig genes and express functional Ig molecules. In this report, we first observed both IgG and IgA staining of normal human foreskin epidermal cells. Besides foreskin, non-prepuce normal skin tissues adjacent to melanoma were also detected by immunohistochemistry. Similar staining of IgG and IgA was observed using commercial anti-IgG, RP215 and anti-IgA (data not shown). However, due to the limit of obtaining absolutely "normal" non-prepuce skin tissues, we used foreskin for further investigation. The IgG staining was very strong in the normal skin epidermis, but not the dermis, when detected by RP215, a mAb which specifically recognizes a unique glycosylated epitope on IgG heavy chain that is over-expressed in some non-B cancer cells [32,33]. Western blotting confirmed that IgG heavy chain was recognized by both RP215 and commercial anti-IgG in epidermal cells. This finding suggests that the epidermis-derived IgG bears a unique glycosylated epitope on its heavy chain, which is different from conventional IgG but similar to non-B cancer cell-derived IgG, and which can be specifically recognized by RP215 instead of commercial anti-IgG antibody.

Ig gene rearrangement and transcription is a prerequisite for Ig expression. To exclude the possibility that extracellular Ig is transferred into epithelial cells through the Fcgamma receptor or the pIgR (polymeric immunoglobulin receptor) on the plasma membrane of epidermal cells [38,39], we looked for rearranged transcripts of $\mathrm{IgG}$ and $\mathrm{IgA}$ genes in the epidermal cells. We excluded possible contamination of the cDNA libraries by B lymphocytes and were still able to amplify functionally rearranged V region gene transcripts for IgG and IgA heavy chains from cDNA of isolated normal epidermis.

We compared the epidermis-derived VDJ rearrangements of $\operatorname{IgG}$ and $\operatorname{IgA}$ heavy chain transcripts of two individuals with B cell-derived Ig. The variable regions of epidermis-derived IgG and IgA displayed conventional VDJ rearrangements like B cell-derived Ig, such as typical $\mathrm{N}$ and $\mathrm{P}$ nucleotides at the junctions between V and D segments, and between D and J segments. However, there were still some differences between VDJ rearrangements in epidermal cells and those in B cells. First, such as other non-B cell-derived Ig, the epidermis-derived IgG and IgA heavy chains had limited rearrangement patterns in each individual, contrasting with the diversity of B cells, but the epidermis from the two individuals whose were tested had different $\mathrm{VH}$ (V region of Ig heavy chains) rearrangements. Second, the V segments used in the two samples were not those commonly used in B cells (the frequencies of these V segment in B cells are: VH1-2: 2.78\%, VH2-5: 1.27\%, VH7-4-1: 1.84\%, VH5-10-1: 0.57\%, and VH1-3: 0.76\% [40]). Third, the epidermal cell-derived IgG and IgA, like Ig derived from epithelial cancer cells or CD33+ myeloblasts sorted from AML patients, seemed not to originate from classical class switching [37,41,42]. IgM-producing cells are precursors of the IgG and IgA producers in classical Ig class switching, so that the Ig $\gamma$ and Ig $\alpha$ gene assembly modes should be similar. However, we did not detect any identical of $\mathrm{V}_{\mathrm{H} \gamma} \mathrm{D}_{\gamma} \mathrm{J}_{\mathrm{H} \gamma}$ and $\mathrm{V}_{\mathrm{H \alpha}} \mathrm{D}_{\alpha} \mathrm{J}_{\mathrm{H} \alpha}$ patterns in the cases studied. This unexpected 
result suggested that Ig $\gamma$ chain was completely different from the Ig $\alpha$ chain in the same epidermal cells and that IgG and IgA production in these cells did not follow the classical class switching mechanism.

The epidermis mainly consists of keratinocytes. Therefore, we used HaCaT, a keratinocyte cell line, to further confirm the expression of $\mathrm{IgG}$ and IgA by epidermal cells. Western blot assay revealed that keratinocyte cell line HaCaT could also produce IgG and IgA. Meanwhile, IgG and IgA heavy chains transcripts were detected in $\mathrm{HaCaT}$ cells.

Although the skin has a tight mechanical barrier, it may be breached by pathogens such as Staph. aureus and Strep. pyogenes. Previous reports indicated that human epithelial cells can spontaneously produce IgM with natural antibody activity by recognizing microbial antigens [6]. We therefore used S. aureus, S. epidermidis, C. albicans and E. coli to test the microbial-binding activity of epidermis-derived IgG or IgA of five individuals for these pathogenic or commensal bacteria. Epidermis-derived Ig from most samples could recognize certain pathogens and showed similar reaction to different pathogens. To further investigate the microbial-binding of epidermis-derived Ig without the potential contamination of B cell-derived Ig, we analyzed the secretion and microbe-recognizing activity of Ig in human keratinocyte cell line HaCaT. HaCaT could spontaneously secret IgG with anti-S. aureus activity and IgA with anti-E. coli and anti-S. aureus activity. However, after microbe stimulation, secreted Ig was obviously elevated and showed similar microbial-binding profiles with Ig extracted from epidermis tissues. Thus, we suggest that microbial-recognizing antibody production by the epidermis constitutes a novel cutaneous defense mechanism that protects from bacterial infection. Interestingly, IgG and IgA secreted by HaCaT stimulated by different microbes showed cross-recognition feature among different microbes. The detailed mechanism needs further investigation. Moreover, epidermis-derived IgG and IgA displayed different microbial-binding patterns. Epidermis-derived IgG bind strongly to $S$. aureus, the leading cause of skin infections, while epidermis-derived IgA could bind both $S$. aureus and the commensal bacterium $S$. epidermidis well. The potential correlation between the different localization or limited VDJ recombination patterns of $\operatorname{IgG}$ and $\operatorname{IgA}$ and their different microbial-binding patterns is still to be discussed.

\section{Experimental Section}

\subsection{Tissue Samples, Bacterial Strains and Cell Line}

Fresh foreskin tissue samples from normal adults were obtained from Peking University Third Hospital. Human peripheral blood from healthy donors was provided by Beijing Red Cross Blood Center. One lung cancer tissue samples with infiltrated B lymphocytes, as the positive control tissue of CD20 immunostaining, was obtained from Peking University Third Hospital.

Escherichia coli (E. coli) strains DH10B and BL21 (Biomed, Beijing, China), Staphylococcus aureus (S. aureus) strains Cowan I (Sigma, St. Louis, MO, USA) and ATCC 25923, Staphylococcus epidermidis (S. epidermidis) clinical isolate strain (donated by Hui Wang, Peking University People's Hospital, Beijing, China), and Candida albicans SC5314 (donated by Ruoyu Li, Peking University First Hospital, Beijing, China) were used in this study. 
Written informed consent was obtained from all donors. All procedures were performed with the ethical approval of the Clinical Research Ethics Committee of the Peking University Health Science Center.

\subsection{Cell Culture}

The human immortalized keratinocyte cell line HaCaT was a gift from Xuejun Zhu (Peking University First Hospital, Beijing, China). HaCaT cells were cultured in Dulbecco's modified Eagle's medium (Invitrogen, Carlsbad, CA, USA) supplemented with 10\% fetal bovine serum (FBS; Hyclone/Thermo Fisher Scientific Inc., Waltham, MA, USA).

\subsection{Immunohistochemistry}

Human tissues were fixed in $10 \%$ formalin, embedded in paraffin, and sectioned. After deparaffinization, antigen retrieval was conducted in Tris-EDTA buffer $\left(\mathrm{pH} \mathrm{9.0)}\right.$ boiled at $120{ }^{\circ} \mathrm{C}$ for 2 min with autoclave. The slides were incubated with 3\% hydrogen peroxide for $5 \mathrm{~min}$, and blocked in 10\% normal goat serum for $10 \mathrm{~min}$. After removing excess blocking buffer, the slides were incubated with RP215 (gift of Gregory Lee), rabbit anti-human IgG antibody (1:3000; Dako, Glostrup, Denmark), rabbit anti-human IgA antibody (1:150; Dako), rabbit anti-human pan-cytokeratin antibody (1:50; Santa Cruz, Santa Cruz, CA, USA), or rabbit anti-CD20 antibody (Epitomics, Burlingame, CA, USA) as the primary antibody, at $37{ }^{\circ} \mathrm{C}$ for $1 \mathrm{~h}$, rinsed, and incubated with horseradish peroxidase-conjugated (HRP) goat anti-mouse/rabbit IgG antibody (1:100; Dako) as the secondary antibody at $37{ }^{\circ} \mathrm{C}$ for $30 \mathrm{~min}$. The bound antibodies were detected using DAB (Dako).

\subsection{Immunofluorescence Staining and Confocal Microscopy Analysis}

For frozen sections, the fresh foreskin tissues were frozen directly in liquid nitrogen, embedded in Tissue-Tek OCT compound (Sakura, San Marcos, CA, USA), sectioned and fixed with acetone. The frozen sections were blocked in 5\% BSA for 30 min and incubated with primary antibodies RP215, rabbit anti-human IgG antibody (1:500; Dako), or rabbit anti-human IgA antibody (1:100; Dako) at room temperature for $1 \mathrm{~h}$, followed by incubation with Dylight 488-conjugated rabbit anti-mouse or goat anti-rabbit IgG antibodies (1:400; Jackson, West Grove, PA, USA) at room temperature for $30 \mathrm{~min}$. Nuclei were stained with Hochest $33342(5 \mu \mathrm{g} / \mathrm{mL}$; Sigma) for $5 \mathrm{~min}$ at room temperature. Images were captured by confocal microscopy using a Leica TCS SP5 imager (Leica Microsystems, Mannheim, Germany).

\subsection{Isolation of Epidermis}

Epidermal sheets were dissociated as previously described [34]. Briefly, following incubation with Dispase II (2.4 U/mL; Roche, Rotkreuz, Switzerland) in DMEM overnight at $4{ }^{\circ} \mathrm{C}$, the epidermal sheet was mechanically separated from the dermis and used for protein extraction or RNA isolation.

\subsection{Isolation of Mononuclear Cells from Peripheral Blood}

Peripheral blood was obtained from healthy donors. Mononuclear cells were isolated from peripheral blood using Ficoll/Hypaque (Second Chemistry Factory, Shanghai, China) density-gradient 
centrifugation, as previously described [37]. Peripheral blood mononuclear cells (PBMCs) at the interface were recovered and washed with PBS, and the isolated PBMCs were used for total RNA extraction.

\subsection{Protein Extraction and Purification}

Separated epidermis was treated with RIPA lysis buffer (1\% Triton X-100, 0.1\% sodium dodecyl sulfate, $1 \%$ sodium deoxycholate, $0.15 \mathrm{M} \mathrm{NaCl}$ and $10 \mathrm{mM}$ Tris (pH 7.2)) with protease inhibitor cocktail (Roche) on ice for $30 \mathrm{~min}$. After centrifugation for $15 \mathrm{~min}$ at $12,000 \times \mathrm{g}$ at $4{ }^{\circ} \mathrm{C}$, the lysate supernatant was collected for Western blotting, enzyme-linked immunosorbent assay, or $\operatorname{IgG}$ purification by affinity chromatography as follows. The lysate was added to protein $\mathrm{G}$ sepharose from which, after washing in PBS, the bound IgG was eluted by $0.1 \mathrm{M}$ Glycine- $\mathrm{HCl}$ ( $\mathrm{pH} 2.4$ ). The fractions collected were analyzed by SDS-PAGE, Western blotting and mass spectrometry (performed by the Beijing Genomics Institute). HaCaT cells were lysed using TSD lysis buffer (1\% sodium dodecyl sulfate, $5 \mathrm{mM}$ dithiothreitol and $50 \mathrm{mM}$ Tris (pH7.5)) with protease inhibitor cocktail (Roche) at room temperature for $20 \mathrm{~min}$. After centrifugation for $15 \mathrm{~min}$ at $12,000 \times \mathrm{g}$ at $4{ }^{\circ} \mathrm{C}$, the lysate supernatant was collected for Western blotting.

\subsection{SDS-PAGE and Western Blotting}

Briefly, protein samples were analyzed in $12.5 \%$ SDS-PAGE and stained with Coomassie Brilliant Blue. For Western blot analysis, the proteins were separated by electrophoresis and transferred from the gel to nitrocellulose membranes, where they were stained indirectly with RP215, goat anti-human IgG antibody (Sigma), or rabbit anti-human IgA antibody (Dako), the primary antibodies listed above, and HRP-conjugated donkey anti-mouse or anti-rabbit IgG antibodies (Jackson) as secondary antibodies. Bound secondary antibodies were visualized by electrochemiluminescence (Thermo, Waltham, MA, USA).

\section{9. $R T-P C R$}

RNA was extracted from HaCaT cells, isolated epidermis or PBMCs following the standard RNeasy Mini Kit (Qiagen, Hilden, Germany) protocol. Reverse transcription was carried out with oligo (dT) primer using Sensiscript RT Kit (Qiagen) according to the manufacturer's instructions. Semi-nested touchdown PCR was then performed to amplify variable region transcripts of IgG and IgA heavy chain, using Phusion DNA Polymerase (Thermo), at annealing temperatures from 60 to $56^{\circ} \mathrm{C}$ for 35 cycles, with sense primers located in variable region (VH1, VH2, VH3, VH4, VH5 and VH6) in both PCR reactions, coupled with antisense primers located in $\mathrm{CH} 1$ domain of $\mathrm{IgG}(\mathrm{C} \gamma \mathrm{CH} 1)$ or $\operatorname{IgA}(\mathrm{CaCH} 1)$ in the first round of PCR and antisense primer in J region $(\mathrm{JH})$ in the second round of PCR. The constant region transcripts of IgG and IgA were amplified at the annealing temperature of $55^{\circ} \mathrm{C}$ for 35 cycles. To exclude B lymphocyte contamination of the skin cDNA libraries, CD19, a B lymphocyte marker, was amplified with the annealing temperature of $50{ }^{\circ} \mathrm{C}$ for 35 cycles. Human PBMCs were used as positive controls of Ig and CD19 amplification. Primers used in this study were listed in Table S3. PCR products were cloned into pGEM-T Easy Vector (Promega, Madison, WI, USA) and sequenced by ABI 3730XL Genetic Analyzer (Applied Biosystem, Foster City, CA, USA). 


\subsection{Sequence Analysis}

All sequences were submitted to the IMGT V-QUEST program to analyze the usage and junctions of Ig heavy chain variable region genes. Alignments with published sequences were by BLAST tool in NCBI (the National Center for Biotechnology Information), and alignments among sequences used Lasergene software (DNAStar, Madison, WI, USA).

\subsection{Microbes Stimulation and Enzyme-Linked Immunosorbent Assay}

To test whether epidermis-derived IgG and IgA could recognize pathogens, we used enzyme-linked immunosorbent assays (ELISA). Microtiter plates were coated with formaldehyde-fixed E. coli strains DH10B or BL21, S. aureus strains Cowan I or ATCC 25923, clinical isolates of S. epidermis, or Candida albicans strain SC5314, diluted in carbonate-bicarbonate coating buffer (pH 9.6) at $50 \mu \mathrm{g} / \mathrm{mL}$ at $4{ }^{\circ} \mathrm{C}$ overnight. After blocking the plates with $3 \%$ BSA for $1 \mathrm{~h}$ at $37{ }^{\circ} \mathrm{C}$, the lysate from individual isolated epidermal tissues were added to the wells $(50 \mu \mathrm{g} /$ well $)$, and the plates were incubated for $2 \mathrm{~h}$ at $37{ }^{\circ} \mathrm{C}$. Rabbit anti-human IgG or IgA antibodies and HRP-conjugated goat anti-rabbit $\mathrm{IgG}$ antibody were used to detect $\mathrm{IgG}$ or $\operatorname{IgA}$, with tetramethylbenzidine as the substrate. OD450 was measured using a microplate reader (Bio-Tek, Winooski, VT, USA).

For further exploration, we stimulated HaCaT with different pathogens and detected the microbial-binding activity of secreted IgG and IgA in supernatant by ELISA. HaCaT was seeded in the 6-well plate. After $12 \mathrm{~h}$, the six formaldehyde-fixed pathogens mentioned above were respectively added to the culture medium at $50 \mu \mathrm{g} / \mathrm{mL}$, vehicle as control. The culture supernatants were collected after another $24 \mathrm{~h}$. ELISA assays were conducted as mentioned above, except that the lysate from epidermal tissues were replaced with the culture supernatants at $50 \mu \mathrm{L} /$ well.

\subsection{Statistical Analysis}

All statistical analyses were performed using GraphPad Prism 6.0 software (Graphpad, San Diego, CA, USA). Differences between groups were calculated by Student's $t$-test and were considered to be statistically significant when $p<0.05$.

\section{Conclusions}

This study illustrated for the first time that normal human epidermal cells, including normal epidermal cells from foreskin tissues and keratinocyte line HaCaT, could spontaneously express functional $\mathrm{IgG}$ and $\mathrm{IgA}$. In epidermis, IgG was found primarily in prickle cells, and IgA was mainly detected in basal cells. In contrast to B cell-derived Ig displaying diversity, epidermal cell-expressed IgG or IgA showed one or two conservative $\mathrm{V}_{\mathrm{H}} \mathrm{DJ}_{\mathrm{H}}$ rearrangements in each individual. Moreover, IgG and IgA from epidermis of the same sample exhibited different VDJ rearrangement patterns. Furthermore, both epidermis-derived IgG and IgA showed potential antibody activity by binding pathogens such as Staphylococcus aureus. However, more studies in vitro are needed to investigate the role of epidermis-derived IgG and IgA in skin local immunity and the detailed mechanism.

Our data indicate that normal human epidermal cells spontaneously express IgG and IgA epidermis-derived IgG and IgA, and we speculate that these Igs participate in skin innate immunity. 


\section{Supplementary Materials}

Supplementary materials can be found at http://www.mdpi.com/1422-0067/16/02/2574/s1.

\section{Acknowledgments}

This work was supported by grants from the National Natural Science Foundation of China (91229102 and 81272237). We thank Huixing He (Peking University Third Hospital) for the sample collection, and Hui Wang (Peking University People's Hospital), Xuejun Zhu (Peking University First Hospital) and Ruoyu Li (Peking University First Hospital) for supplying the cell line, bacteria and fungi strains.

\section{Author Contributions}

As the corresponding author, Xiaoyan Qiu planed and supervised the whole study. Dongyang Jiang and Jing Ge participated in the research design, performed most experiments including immunohistochemistry assay, Western blot, RT-PCR and so on, and wrote the manuscript. Qinyuan Liao, Junfan Ma, Yang Liu, Chong Wang and Weiyan Xu were partly involved in immunohistochemistry assay, Western blot analysis and the manuscript writing. Jing Huang, Jie Zheng and Wenwei Shao provided suggestions and technical supports. Gregory Lee discovered and provided the RP215 antibody generously.

\section{Conflicts of Interest}

The authors declare no conflict of interest.

\section{References}

1. Shishido, S.N.; Varahan, S.; Yuan, K.; Li, X.; Fleming, S.D. Humoral innate immune response and disease. Clin. Immunol. 2012, 144, 142-158.

2. Li, M.; Feng, D.Y.; Ren, W.; Zheng, L.; Zheng, H.; Tang, M.; Cao, Y. Expression of immunoglobulin $\kappa$ light chain constant region in abnormal human cervical epithelial cells. Int. J. Biochem. Cell Biol. 2004, 36, 2250-2257.

3. Geng, L.Y.; Shi, Z.Z.; Dong, Q.; Cai, X.H.; Zhang, Y.M.; Cao, W.; Peng, J.P.; Fang, Y.M.; Zheng, L.; Zheng, S. Expression of SNC73, a transcript of the immunoglobulin $\alpha-1$ gene, in human epithelial carcinomas. World J. Gastroenterol. 2007, 13, 2305-2311.

4. Zhang, S.; Mao, Y.; Huang, J.; Ma, T.; Zhang, L.; Zhu, X.; Zheng, J.; Wu, L.; Yin, C.C.; Qiu, X. Immunoglobulin gene locus events in epithelial cells of lactating mouse mammary glands. Cell. Mol. Life Sci. 2010, 67, 985-994.

5. Zhang, L.; Hu, S.; Korteweg, C.; Chen, Z.; Qiu, Y.; Su, M.; Gu, J. Expression of immunoglobulin $\mathrm{G}$ in esophageal squamous cell carcinomas and its association with tumor grade and Ki67. Hum. Pathol. 2012, 43, 423-434. 
6. Hu, F.; Zhang, L.; Zheng, J.; Zhao, L.; Huang, J.; Shao, W.; Liao, Q.; Ma, T.; Geng, L.; Yin, C.C.; et al. Spontaneous production of immunoglobulin $\mathrm{m}$ in human epithelial cancer cells. PLoS One 2012, 7, e51423.

7. Niu, N.; Zhang, J.; Huang, T.; Sun, Y.; Chen, Z.; Yi, W.; Korteweg, C.; Wang, J.; Gu, J. IgG expression in human colorectal cancer and its relationship to cancer cell behaviors. PLoS One 2012, 7, e47362.

8. Huang, J.; Zhang, L.; Ma, T.; Zhang, P.; Qiu, X. Expression of immunoglobulin gene with classical V-(D)-J rearrangement in mouse testis and epididymis. J. Histochem. Cytochem. 2009, 57, 339-349.

9. Zhao, Y.; Liu, Y.; Chen, Z.; Korteweg, C.; Gu, J. Immunoglobulin g (IgG) expression in human umbilical cord endothelial cells. J. Histochem. Cytochem. 2011, 59, 474-488.

10. Kang, B.Y.; Hu, C.; Prayaga, S.; Khaidakov, M.; Sawamura, T.; Seung, K.B.; Mehta, J.L. Lox-1 dependent over-expression of immunoglobulins in cardiomyocytes in response to angiotensin II. Biochem. Biophys. Res. Commun. 2009, 379, 395-399.

11. Huang, J.; Sun, X.; Mao, Y.; Zhu, X.; Zhang, P.; Zhang, L.; Du, J.; Qiu, X. Expression of immunoglobulin gene with classical V-(D)-J rearrangement in mouse brain neurons. Int. J. Biochem. Cell Biol. 2008, 40, 1604-1615.

12. Niu, N.; Zhang, J.; Guo, Y.; Zhao, Y.; Korteweg, C.; Gu, J. Expression and distribution of immunoglobulin $\mathrm{G}$ and its receptors in the human nervous system. Int. J. Biochem. Cell Biol. 2011, 43, 556-563.

13. Chen, Z.; Li, J.; Xiao, Y.; Zhang, J.; Zhao, Y.; Liu, Y.; Ma, C.; Qiu, Y.; Luo, J.; Huang, G.; et al. Immunoglobulin G locus events in soft tissue sarcoma cell lines. PLoS One 2011, 6, e21276.

14. Niu, N.; Zhang, J.; Sun, Y.; Wang, S.; Sun, Y.; Korteweg, C.; Gao, W.; Gu, J. Expression and distribution of immunoglobulin $\mathrm{G}$ and its receptors in an immune privileged site: The eye. Cell. Mol. Life Sci. 2011, 68, 2481-2492.

15. Hu, D.; Zheng, H.; Liu, H.; Li, M.; Ren, W.; Liao, W.; Duan, Z.; Li, L.; Cao, Y. Immunoglobulin expression and its biological significance in cancer cells. Cell. Mol. Immunol. 2008, 5, 319-324.

16. Zheng, H.; Li, M.; Ren, W.; Zeng, L.; Liu, H.D.; Hu, D.; Deng, X.; Tang, M.; Shi, Y.; Gong, J.; et al. Expression and secretion of immunoglobulin $\alpha$ heavy chain with diverse VDJ recombinations by human epithelial cancer cells. Mol. Immunol. 2007, 44, 2221-2227.

17. Duan, Z.; Zheng, H.; Xu, S.; Jiang, Y.; Liu, H.; Li, M.; Hu, D.; Li, W.; Bode, A.M.; Dong, Z.; et al. Activation of the Ig I $\alpha 1$ promoter by the transcription factor Ets-1 triggers Ig I $\alpha 1-\mathrm{C} \alpha 1$ germline transcription in epithelial cancer cells. Cell. Mol. Immunol. 2014, 11, 197-205.

18. Wang, J.; Lin, D.; Peng, H.; Huang, Y.; Huang, J.; Gu, J. Cancer-derived immunoglobulin G promotes tumor cell growth and proliferation through inducing production of reactive oxygen species. Cell Death Dis. 2013, 4, e945.

19. Qiu, X.; Zhu, X.; Zhang, L.; Mao, Y.; Zhang, J.; Hao, P.; Li, G.; Lv, P.; Li, Z.; Sun, X.; et al. Human epithelial cancers secrete immunoglobulin $G$ with unidentified specificity to promote growth and survival of tumor cells. Cancer Res. 2003, 63, 6488-6495.

20. Wen, Y.J.; Mancino, A.; Pashov, A.; Whitehead, T.; Stanley, J.; Kieber-Emmons, T. Antigen binding of human IgG Fabs mediate ERK-associated proliferation of human breast cancer cells. DNA Cell Biol. 2005, 24, 73-84. 
21. Liang, P.Y.; Li, H.Y.; Zhou, Z.Y.; Jin, Y.X.; Wang, S.X.; Peng, X.H.; Ou, S.J. Over-expression of immunoglobulin $\mathrm{G}$ prompts cell proliferation and inhibits cell apoptosis in human urothelial carcinoma. Tumour Biol. 2013, 34, 1783-1791.

22. Pan, B.; Zheng, S.; Liu, C.; Xu, Y. Suppression of $I G H G 1$ gene expression by siRNA leads to growth inhibition and apoptosis induction in human prostate cancer cell. Mol. Biol. Rep. 2013, 40, 27-33.

23. Harder, J.; Bartels, J.; Christophers, E.; Schroder, J.M. A peptide antibiotic from human skin. Nature 1997, 387, 861.

24. Carmona-Ribeiro, A.M.; de Melo Carrasco, L.D. Novel formulations for antimicrobial peptides. Int. J. Mol. Sci. 2014, 15, 18040-18083.

25. Ryu, S.; Song, P.I.; Seo, C.H.; Cheong, H.; Park, Y. Colonization and infection of the skin by $s$. Aureus: Immune system evasion and the response to cationic antimicrobial peptides. Int. J. Mol. Sci. 2014, 15, 8753-8772.

26. Coruh, G.; Mason, D.Y. Serum proteins in human squamous epithelium. Br. J. Dermatol. 1980, 102, 497-505.

27. Gilliam, J.N.; Cheatum, D.E.; Hurd, E.R.; Stastny, P.; Ziff, M. Immunoglobulin in clinically uninvolved skin in systemic lupus erythematosus: Association with renal disease. J. Clin. Investig. 1974, 53, 1434-1440.

28. Mshana, R.N.; Humber, D.P.; Belehu, A.; Harboe, M. Immunohistological studies of skin biopsies from patients with lepromatous leprosy. J. Clin. Immunol. 1983, 3, 22-29.

29. Yaoita, H.; Briggaman, R.A.; Lawley, T.J.; Provost, T.T.; Katz, S.I. Epidermolysis bullosa acquisita: Ultrastructural and immunological studies. J. Investig. Dermatol. 1981, 76, 288-292.

30. Blenkinsopp, W.K.; Clayton, R.J.; Haffenden, G.P. Immunoglobulin and complement in normal skin. J. Clin. Pathol. 1978, 31, 1143-1146.

31. Zhu, X.; Li, C.; Sun, X.; Mao, Y.; Li, G.; Liu, X.; Zhang, Y.; Qiu, X. Immunoglobulin mRNA and protein expression in human oral epithelial tumor cells. Appl. Immunohistochem. Mol. Morphol. 2008, 16, 232-238.

32. Lee, G.; Laflamme, E.; Chien, C.H.; Ting, H.H. Molecular identity of a pan cancer marker, CA215. Cancer Biol. Ther. 2008, 7, 2007-2014.

33. Lee, G. Cancer cell-expressed immunoglobulins: CA215 as a pan cancer marker and its diagnostic applications. Cancer Biomark. 2009, 5, 137-142.

34. Schneider, T.E.; Barland, C.; Alex, A.M.; Mancianti, M.L.; Lu, Y.; Cleaver, J.E.; Lawrence, H.J.; Ghadially, R. Measuring stem cell frequency in epidermis: A quantitative in vivo functional assay for long-term repopulating cells. Proc. Natl. Acad. Sci. USA 2003, 100, 11412-11417.

35. Kanno, H.; Kubo, A.; Yoshizumi, T.; Mikami, T.; Maegawa, J. Isolation of multipotent nestin-expressing stem cells derived from the epidermis of elderly humans and TAT-VHL peptide-mediated neuronal differentiation of these cells. Int. J. Mol. Sci. 2013, 14, 9604-9617.

36. Van Dongen, J.J.; Langerak, A.W.; Bruggemann, M.; Evans, P.A.; Hummel, M.; Lavender, F.L.; Delabesse, E.; Davi, F.; Schuuring, E.; Garcia-Sanz, R.; et al. Design and standardization of PCR primers and protocols for detection of clonal immunoglobulin and T-cell receptor gene recombinations in suspect lymphoproliferations: Report of the BIOMED-2 concerted action BMH4-CT98-3936. Leukemia 2003, 17, 2257-2317. 
37. Zheng, J.; Huang, J.; Mao, Y.; Liu, S.; Sun, X.; Zhu, X.; Ma, T.; Zhang, L.; Ji, J.; Zhang, Y.; et al. Immunoglobulin gene transcripts have distinct $\mathrm{V}_{\mathrm{H}} \mathrm{JJ}_{\mathrm{H}}$ recombination characteristics in human epithelial cancer cells. J. Biol. Chem. 2009, 284, 13610-13619.

38. Tigalonowa, M.; Bjerke, J.R.; Matre, R. Fc gamma-receptors on langerhans' cells and keratinocytes in suspension from normal skin characterized using soluble immune complexes and monoclonal antibodies. Acta Derm. Venereol. 1991, 71, 99-103.

39. Huff, J.C. Epithelial polymeric immunoglobulin receptors. J. Investig. Dermatol. 1990, 94, 74S-78S.

40. Glanville, J.; Zhai, W.; Berka, J.; Telman, D.; Huerta, G.; Mehta, G.R.; Ni, I.; Mei, L.; Sundar, P.D.; Day, G.M.; et al. Precise determination of the diversity of a combinatorial antibody library gives insight into the human immunoglobulin repertoire. Proc. Natl. Acad. Sci. USA 2009, 106, 20216-20221.

41. Huang, J.; Sun, X.; Gong, X.; He, Z.; Chen, L.; Qiu, X.; Yin, C.C. Rearrangement and expression of the immunoglobulin $\mu$-chain gene in human myeloid cells. Cell. Mol. Immunol. 2014, 11, 94-104.

42. Qiu, X.; Sun, X.; He, Z.; Huang, J.; Hu, F.; Chen, L.; Lin, P.; You, M.J.; Medeiros, L.J.; Yin, C.C. Immunoglobulin $\gamma$ heavy chain gene with somatic hypermutation is frequently expressed in acute myeloid leukemia. Leukemia 2013, 27, 92-99.

(C) 2015 by the authors; licensee MDPI, Basel, Switzerland. This article is an open access article distributed under the terms and conditions of the Creative Commons Attribution license (http://creativecommons.org/licenses/by/4.0/). 